${ }^{2}$ Institute of Geophysics and Meteorology, University of Cologne, Cologne, Germany

\title{
Nocturnal stratiform cloudiness during the West African monsoon
}

\author{
J. M. Schrage ${ }^{1}$, S. Augustyn ${ }^{1}$, and A. H. Fink ${ }^{2}$ \\ With 9 Figures \\ Received October 7, 2005; revised December 19, 2005; accepted February 16, 2006 \\ Published online: July 31, 2006 (C) Springer-Verlag 2006
}

\begin{abstract}
Summary
An analysis of METEOS AT satellite images and synoptic reports from Parakou, Benin suggests that those nights that lack deep convection during the West African monsoon are often either completely clear or completely overcast at low levels. Using radiosonde observations gathered at Parakou during the IMPETUS field campaign of the summer of 2002 and ECMWF operational analyses, the composite structure of the atmosphere for both cloudy and clear nights is presented. Cloudy nights are found to occur when turbulent processes result in large-scale speed convergence in the boundary layer and a positive net moisture flux convergence. Conversely, the clear conditions occur when a nocturnal inversion decouples the boundary layer from the surface. The cloudy and clear conditions are also shown to be related to large-scale changes in the configurations of the African Easterly Jet and the Tropical Easterly Jet, although the nature of this relationship remains unclear.
\end{abstract}

\section{Introduction}

Tropical West Africa experiences a summer monsoon regime that is characterized by an abrupt shift in the Intertropical Convergence Zone (ITCZ) from about $5^{\circ} \mathrm{N}$ to about $10^{\circ} \mathrm{N}$ in late June or early July (Sultan and Janicot, 2003). The corresponding monsoon southwesterlies transport moisture from the equatorial Atlantic poleward, while the hot Saharan Air Layer overruns the monsoon layer, providing strong Convective Inhibition (CIN) at sub-Saharan latitudes. When combined with the strong shear associated with the African Easterly Jet (AEJ) and the Tropical Easterly Jet (TEJ), this environment favors highly organized convective systems such as squall lines. The meridional temperature gradient between the Sahara and the equatorial Atlantic encourages the growth of waves in the AEJ on a variety of time scales. Much recent research (e.g., Redelsperger et al, 2002; Fink and Reiner, 2003; Hsieh and Cook, 2005) in the region has focused on development of an integrated model of the roles of the AEJ, African Easterly Waves (AEWs), squall lines, and the TEJ. Other foci have been the impact of changes in the land surface characteristics on the monsoon climate (Zeng et al, 1999; Douville et al, 2001; Douville, 2002) and synoptic variability (Taylor and Clark, 2001; Taylor et al, 2005). In particular, the role of the atmospheric dust loading over North Africa on local climate features such as the AEJ (Tompkins et al, 2005) and on Atlantic tropical cyclogenesis (Dunion and Veldon, 2004) has been a prominent topic of research. Relatively few studies are concerned with the diurnal cycle of the West African monsoon flow (e.g., Farquharson, 1939) and the role 
of the cloudy zone, located south of the main activity belt of mesoscale convective systems (MCSs, e.g., Fink and Reiner, 2003). It is in this cloudy zone, often characterized by stratus and stratocumulus cloud decks, through which the bulk of the moisture evaporating from the surrounding ocean water is advected inland within the lowest 1-3 kilometers of the atmosphere (Lamb, 1983; Cadet and Nnoli, 1987). This moisture later precipitates out in the MCSs, which bring $80-90 \%$ of the annual rainfall to the Sahelian region (Dhonneur, 1981; Mathon et al, 2002). The degree of vertical mixing in the atmospheric boundary layer in this cloudy zone is crucial in determining the ratio of moisture recycled over land vs. moisture originating from evaporation from the surrounding waters. This is a crucial factor in assessing the role of land surface degradation in the southern wet zone for precipitation changes in the Sahel. Embedded in this general context, the present study is aimed at relating striking day-to-day differences in the nocturnal stratiform cloudiness to large-scale changes in West African monsoon flow and local boundary-layer stability variations.

To achieve this goal, data from a field experiment in West Africa, conducted by a consortium of German universities during the summer of 2002, are used. The program, known as IMPETUS ("Integratives Management-Projekt für einen effizienten und tragfähigen Umgang mit Süßwasser in West Afrika", translated as
"An integrated approach to the efficient management of scarce water resources in West Africa"), operated a radiosonde station at the synoptic station at Parakou $\left(9^{\circ} 21^{\prime} \mathrm{N}, 2^{\circ} 37^{\prime} \mathrm{E}\right)$ in Benin. Since the beginning of the 1980s, no upper-air station has been operational during an entire rainy season in the West African Soudanian zone (i.e., $9^{\circ}-12^{\circ} \mathrm{N}$ ). Thus the twice-daily, $10 \mathrm{~m}$ resolution vertical profiles of temperature, humidity, winds, and pressure represent a unique data set to study the local boundary layer structure of the atmosphere during clear and cloudy nights from April to October of 2002. The data from the soundings were transmitted in real-time to ECMWF (European Centre for Medium-Range Weather Forecasts), where they were assimilated into the operational analyses that are used in this study to examine the large-scale processes. Schrage et al (2006) examined records provided by the ECMWF and found that the data assimilated from the special station at Parakou greatly improved the low-level wind field. The $4 \mathrm{dVar}$ scheme generally accepted the winds and thermodynamic observations in environments without deep, moist convection.

In an inspection of the complete record of surface synoptic reports from Parakou and METEOSAT satellite images, it became apparent that a number of cloud regimes are commonly found in sub-Sahelian West African at night. While a variety of MCSs could be identified, the less disturbed atmospheres also demonstrated intriguing variety. Among non-precipitating

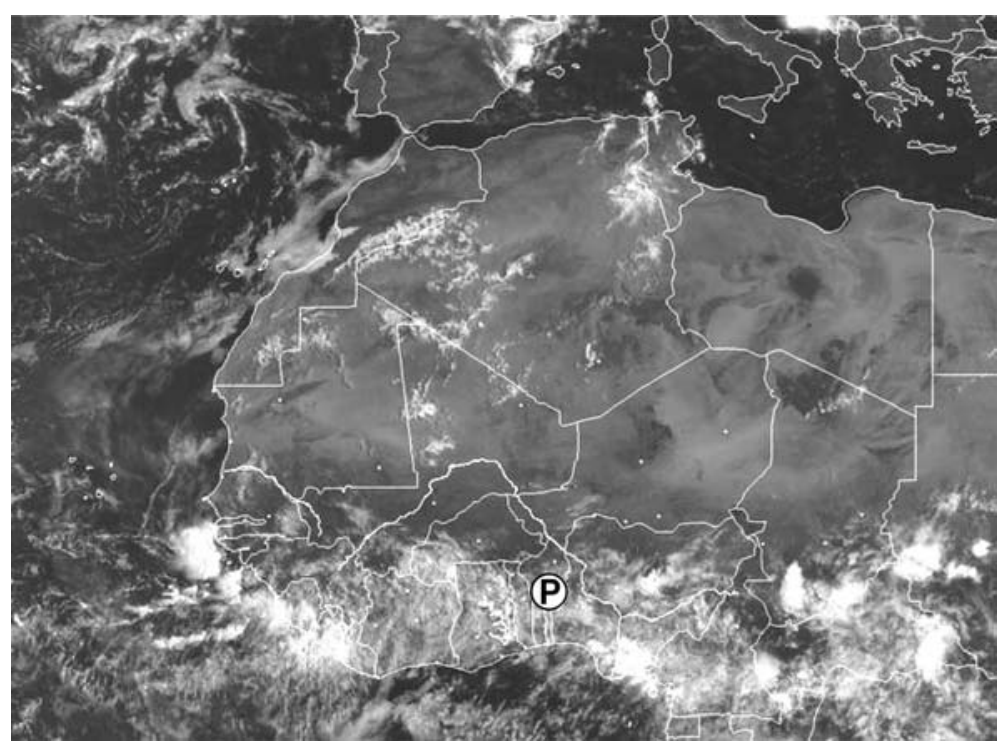

Fig. 1. METEOS AT visible satellite image for 0900 UTC 22 August 2002, showing much of sub-Sahelian West Africa with stratiform clouds. The location of Parakou is indicated with a "P" 
nights, the 0000 UTC (which is approximately local midnight in Parakou) synoptic observations noted completely clear skies at low levels on $27 \%$ of the nights between July and September. In contrast, on $24 \%$ of the non-precipitating nights between July and September the Parakou observation notes stratiform cloud cover of 7 oktas or more at low levels. This coverage could be quite extensive over a broad region of the wet zone of West Africa, as suggested in the visible satellite image presented in Fig. 1. Personal communication with observers in the field during IMPETUS revealed that such stratiform cloud cover was typically very low and propagating rapidly from south to north.

Based on the 0000 UTC synoptic observations at Parakou, a list of 11 cloudy nights and 12 clear nights between 1 July 2002 and 30 September 2002 was compiled and is presented in Table 1. The dates are quite randomly distributed throughout all phases of the monsoon season. The goal of this study is to composite the local and macroscale features of the atmosphere on both cloudy and clear nights to infer the various conditions that favor or suppress nocturnal stratiform cloud coverage during the West African monsoon. For the purposes of this study, the cloud coverage is believed to be indicative of the large scale circulation, rather than a cause.

The data and computational procedures used in this study are described in Sect. 2. Sections 3 and 4 describe the results from the radiosonde composites and the ECMWF operational model

Table 1. Dates of 11 cloudy and 12 clear nights in Parakou, Benin, between 1 July 2002 and 31 September 2002

Dates of cloudy and clear nights in Parakou

\begin{tabular}{|c|c|}
\hline Cloudy & Clear \\
\hline 4 July 2002 & 5 July 2002 \\
\hline 10 July 2002 & 8 July 2002 \\
\hline 17 July 2002 & 11 July 2002 \\
\hline 30 July 2002 & 20 July 2002 \\
\hline 1 August 2002 & 27 July 2002 \\
\hline 2 August 2002 & 3 August 2002 \\
\hline 6 August 2002 & 10 August 2002 \\
\hline 7 August 2002 & 28 August 2002 \\
\hline 22 August 2002 & 3 September 2002 \\
\hline 27 August 2002 & 8 September 2002 \\
\hline \multirow[t]{2}{*}{30 September 2002} & 17 September 2002 \\
\hline & 23 September 2002 \\
\hline
\end{tabular}

composites, respectively. The results are summarized in Sect. 5, along with suggestions for further work.

\section{Data and computational procedures}

\subsection{Radiosonde data from Parakou}

High-resolution, vertical profiles of temperature, humidity, pressure, and wind were taken by the IMPETUS radiosonde campaign at Parakou. These twice-daily (00 and 1200 UTC) observations were made at the only operational radiosonde station in the Soudanian climate zone at that time. The instrumentation and procedures implemented to minimize the sonde's dry bias in the lowest few hundred meters during the radiosonde campaign are described in detail in Fink et al (2006).

\subsection{ECMWF operational analyses}

Large-scale kinematic processes and moisture fields were examined using analyses from the ECMWF operational model. The six-hourly ECMWF isobaric analyses of the meridional and zonal winds and the relative vorticity were available at $1^{\circ} \times 1^{\circ}$ resolution, although only the 0000 UTC values were used. Values from the 1000, 925, 850, 700, 500, 400, 300, 200 and $100 \mathrm{hPa}$ isobaric levels were used in construction of cross-sectional diagrams. The ECMWF analyses have been shown to adequately depict the synoptic and diurnal patterns of circulation features in tropical West Africa (e.g., Taylor et al, 2005).

\section{Composite radiosonde results}

The radiosonde observations taken on 11 cloudy nights and 12 clear nights were composited and are shown in Fig. 2. While both profiles suggested a very moist lower atmosphere, the clear nights (dashed lines) were considerably drier than the overcast nights (solid lines) were. Therefore, air parcels from the surface would need to be lifted considerably higher on the clear nights to reach their Lifted Condensation Level (LCL). Because the base of the cloud layer was observed at different altitudes on the various individual cloudy nights, the process of compositing the 


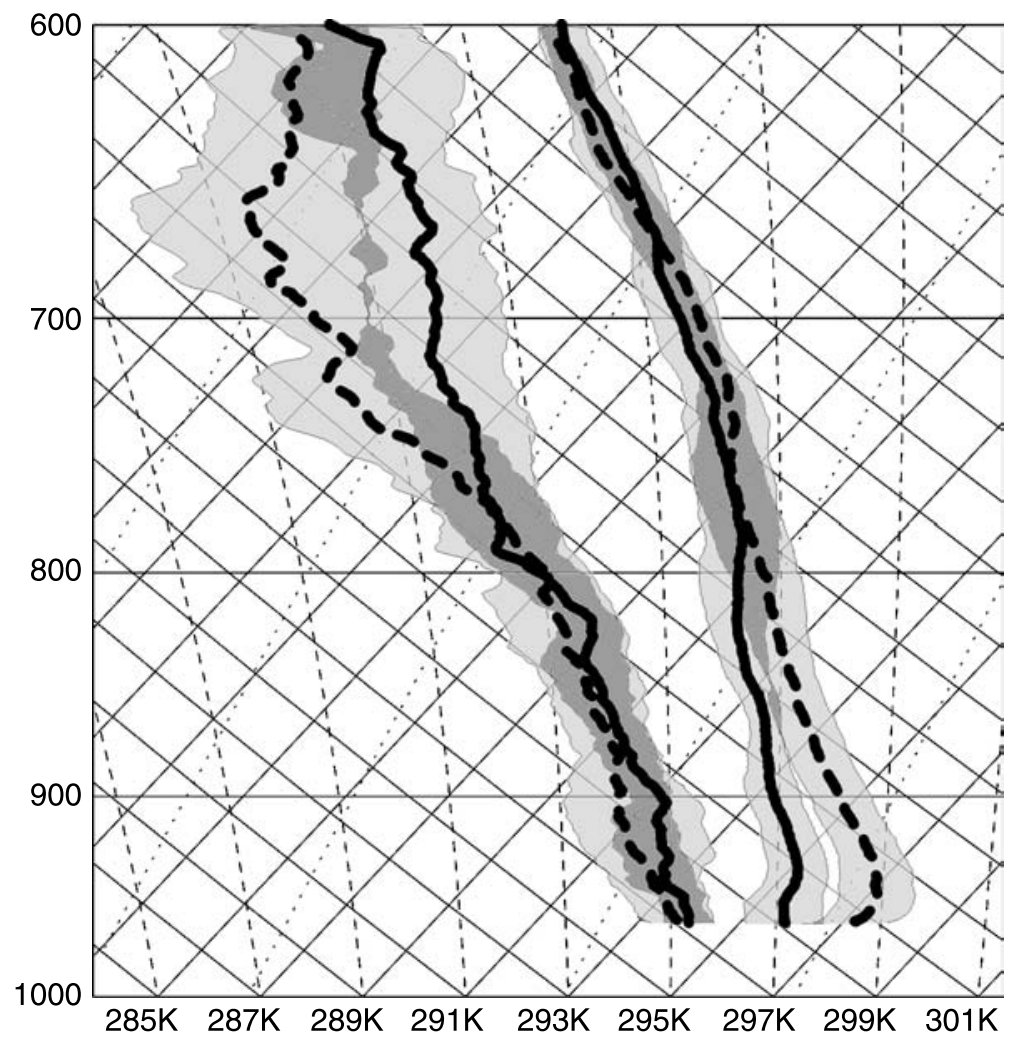

Fig. 2. Composite skew $T-\log P$ diagrams of temperature and dewpoint observations below $600 \mathrm{hPa}$ for 11 cloudy nights (solid) and 12 clear nights (dashed). The light shading indicates the range of \pm 2 standard deviations about the composite mean, with darker shading suggesting overlap between these ranges profiles for the cloudy nights tended to result in a broad layer of low (but non-zero) dewpoint depressions between about 900 and $750 \mathrm{hPa}$. An examination of the profiles for the individual nights (not shown) reveals that the profiles tended to be saturated in narrow layers as the radiosonde passed through the cloud layer somewhere between 900 and $750 \mathrm{mb}$.

This lifting was less likely on the clear nights, due to the formation of a nocturnal inversion in the lower 10-20 hPa. An examination of the individual skew $T-\log P$ diagrams for each of the soundings (not shown) revealed that the tops of these inversions were typically quite low, averaging around $950 \mathrm{hPa}$, with their bases at or extremely near the surface. In contrast, on the cloudy nights a superadiabatic temperature profile-typical during the day, but less expected at night-existed near the surface. Individual soundings revealed that the superadiabatic layer was quite shallow, never reaching as high as $950 \mathrm{hPa}$, but a well-mixed layer typically existed above this layer, occasionally reaching a pressure altitude of $900 \mathrm{hPa}$. Buoyant production of thermals could continue under these conditions, and these thermals would be more likely to reach their LCL than under the conditions shown for the clear night composite. Lloyd et al (1997) demonstrated that the stability of nocturnal low-level air in the Sahel was directly associated with cloud cover.

Several important features of the vertical structure of the atmosphere were lost in the compositing of multiple nights and, therefore, could only be revealed by an analysis of individual soundings. One such feature was the presence of dry layers of air aloft. The overall dryness aloft in the composite of the clear nights was found to be due to individual layers of northerly flow and high dewpoint depression. These intrusions of air from the Saharan Air Layer (SAL) greatly reduced the overall moisture in the profile and typically occurred slightly above small inversions in the temperature profile. These layers were by no means completely absent on the cloudy nights, but they were less thick, less common, and not as dry.

Further insight into the structure of the atmosphere can be gained by comparing profiles of individual variables for the cloudy and clear nights (Fig. 3a). The AEJ was quite apparent in the zonal wind on the clear nights at about $700 \mathrm{hPa}$, but much less so on the cloudy nights. Below the AEJ, both cloudy and clear nights 

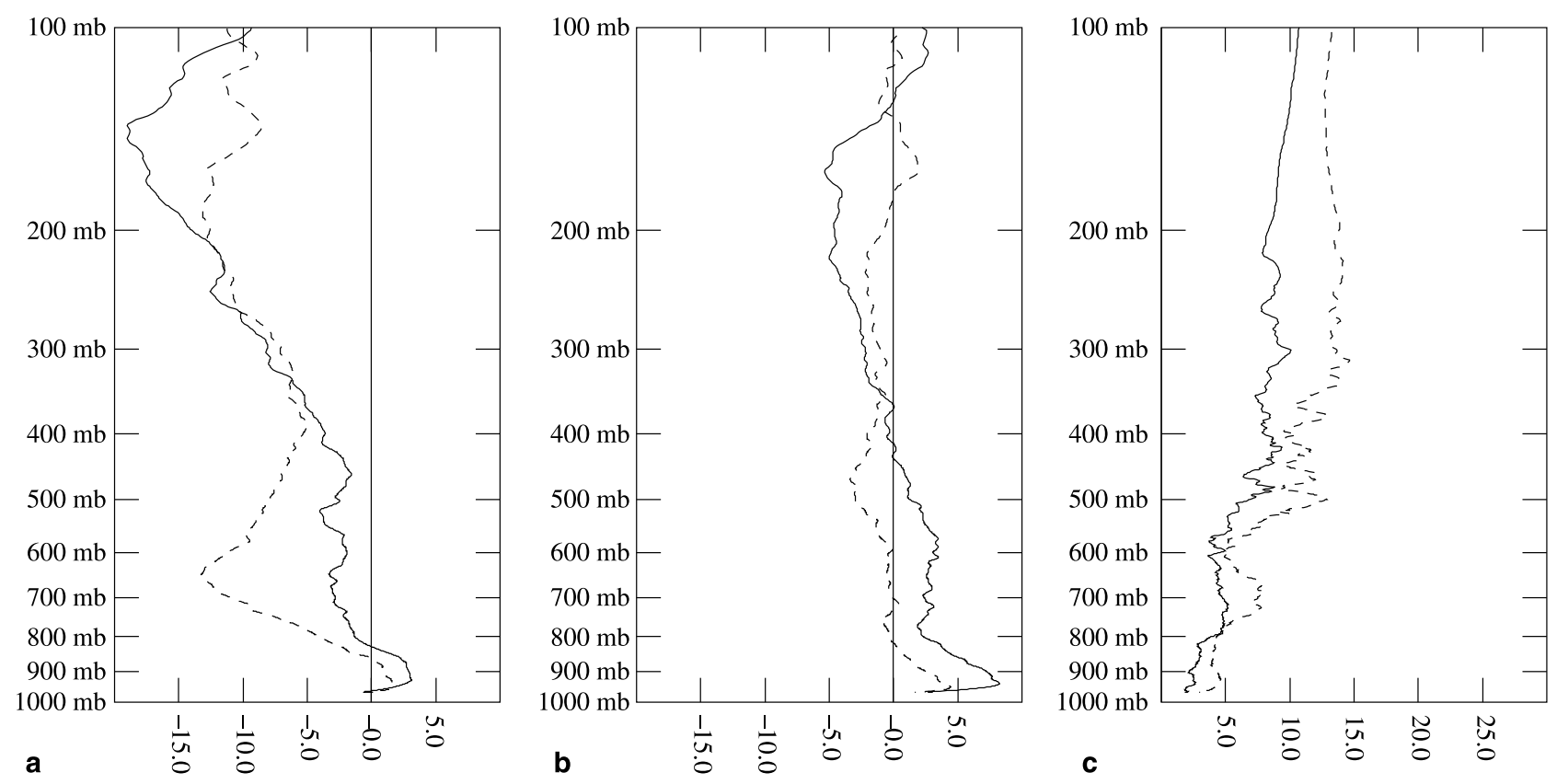

Fig. 3. Composite profiles of (a) zonal wind, (b) meridional wind, and (c) dewpoint depression for 11 cloudy nights (solid) and 12 clear nights (dashed) at Parakou

exhibited weak westerly (i.e., monsoon) flow near the surface, but this flow was stronger on the cloudy nights. At about $150 \mathrm{hPa}$, which was the level of the TEJ, considerably stronger easterlies were observed on the cloudy nights than on the clear nights. The changes in the zonal wind at all these levels may reflect different modes of the large scale meteorology of the West African monsoon on these nights.

Deep southerly flow between the surface and $400 \mathrm{hPa}$ with a distinct low level speed maximum at about $900 \mathrm{hPa}$ was noted on the cloudy nights (Fig. 3b), whereas the southerlies were limited to the lowest $150 \mathrm{hPa}$ on the clear nights (Fig. 3b). Visual observations of low cloud motions taken during the experiment corroborate an unusual, strong, low level jet-like southwesterly flow during cloudy nights and mornings as shown in Fig. 3a. In contrast, the low-level monsoon flow increased and peaked towards the surface during clear nights (Fig. 3b). Another difference between the cloudy and clear nights was also revealed at the $700 \mathrm{hPa}$ level, where the composite meridional flow was approximately $0 \mathrm{~m} \mathrm{~s}^{-1}$ on the clear nights but $3-5 \mathrm{~m} \mathrm{~s}^{-1}$ on the cloudy nights. The interpretation of this result is that clear nights occurred in conjunction with zonal flow in the AEJ, whereas southerly flow in the
AEJ was consistent with the region east of a trough and west of a ridge in the AEJ.

Differences in the moisture profiles on cloudy and clear nights were noted in Fig. 3c. At all levels, the clear nights were drier than the cloudy nights. Since the nocturnal stratiform cloud decks were quite shallow, the differences in the moisture profiles in the middle and upper troposphere must have reflected large-scale differences in the overall monsoon system. It may be the case that cloudy nights had more moisture aloft due to moisturizing of the upper atmosphere by previous convective systems; conversely, the dryness aloft on the clear nights may have represented intrusions of the SAL, which would certainly be consistent with the northerly flow on the clear nights above $600 \mathrm{hPa}$.

The shallow nature of the nocturnal stratiform cloud cover suggests that the dynamics of the atmosphere below the AEJ may be fundamental to cloud formation or suppression. Hodographs of the composite wind structure below $700 \mathrm{hPa}$ are shown in Fig. 4. Both the cloudy nights and the clear nights exhibited some shear and veering in the lowest $10-15 \mathrm{hPa}$ of the atmosphere, presumably due chiefly to Ekman processes in the lowest few tens of meters of the boundary layer. On cloudy nights, the flow rapidly increased with 

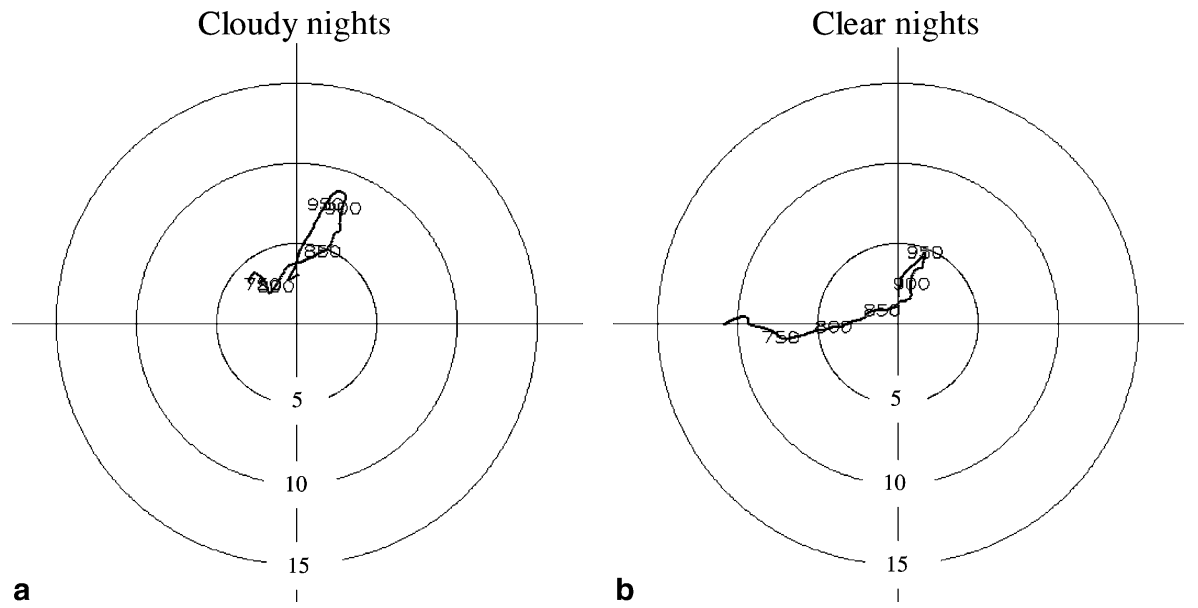

Fig. 4. Composite hodographs of the winds from the surface to $700 \mathrm{hPa}$ for (a) 11 cloudy nights, and (b) 12 clear nights. Units are $\mathrm{m} \mathrm{s}^{-1}$

respect to height, with the strongest southwesterly flow between the 950 and $900 \mathrm{hPa}$ levels. Overall wind speed decreased above this pressure altitude, and the winds weakly veered to the southwest. In contrast, on clear nights the composite southwesterlies never exceeded $5 \mathrm{~m} \mathrm{~s}^{-1}$,
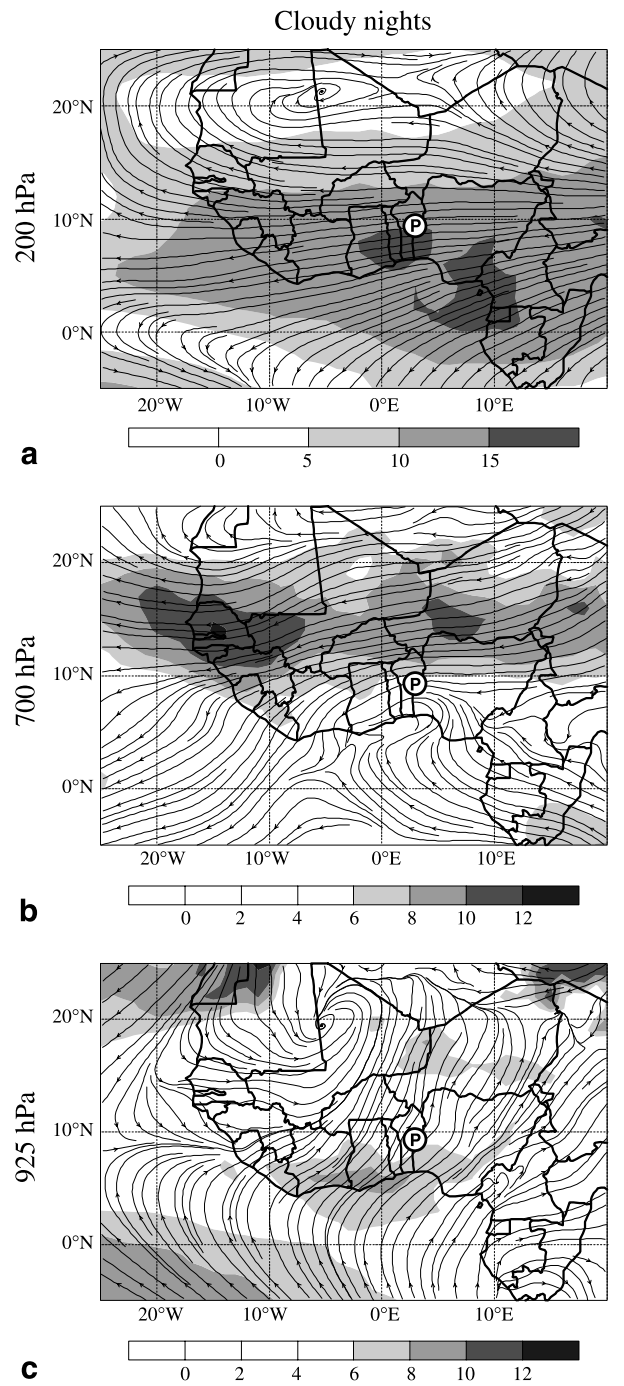
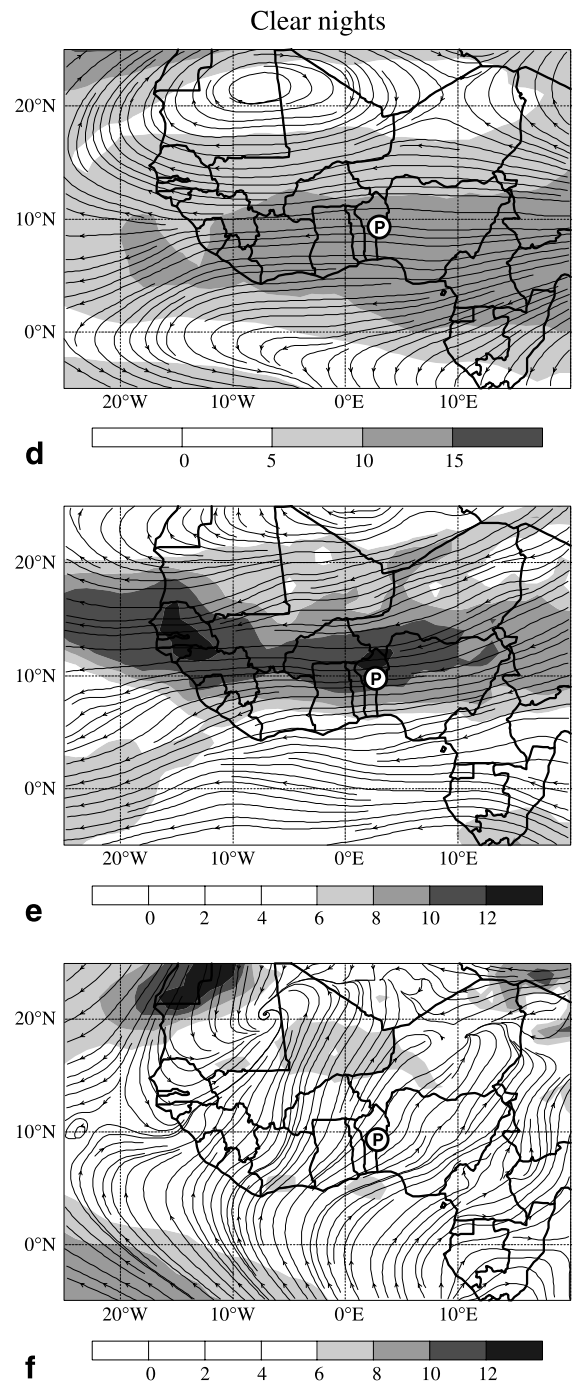

Fig. 5. Streamlines and isotachs of the flow at (a) 200, (b) 700, and (c) $925 \mathrm{hPa}$ according to ECMWF operational analyses, composited for 11 cloudy nights. Panels (d), (e), and (f) are the same as panels (a), (b), (c), respectively, except composited for 12 clear nights. Units are $\mathrm{m} \mathrm{s}^{-1}$. The location of Parakou is indicated with a "P" 
and the flow was strongly sheared. The flow became easterly and reached a velocity of more than $10 \mathrm{~m} \mathrm{~s}^{-1}$ by $700 \mathrm{hPa}$.

\section{ECMWF results}

\subsection{Kinematics}

Streamlines and isotachs of the composite flow on cloudy and clear nights are presented in Fig. 5. At $925 \mathrm{hPa}$ (Fig. 5c), both clear and cloudy nights exhibited the key expected features of the monsoon regime, including cross-equatorial flow, a buffer zone with anticyclonic curvature, and large scale confluence into a heat low centered near $20^{\circ} \mathrm{N}$. These plots are composites of the ECMWF analyses at 0000 UTC, when the monsoon winds are at or near their diurnal peak in the model (Parker et al, 2005). The primary difference between the cloudy and clear nights appears to be that the onshore flow was considerably stronger on the cloudy nights. This indicates that the strong southwesterly peak at $925 \mathrm{hPa}$ evident in the composite soundings during cloudy nights at Parakou (Fig. 3a) was embedded in a continental-scale surge of the low-level monsoonal westerlies. Note, however, that wind speeds in the ECMWF analysis around Parakou are weaker than the balloon winds (i.e., less than $6 \mathrm{~m} \mathrm{~s}^{-1}$ ). Only along the Guinea Coast were winds in excess of $8 \mathrm{~m} \mathrm{~s}^{-1}$ analyzed.

The ECMWF results at $700 \mathrm{hPa}$ (Fig. 5b and e) confirm that the AEJ was more zonal on the clear nights than on the cloudy nights, as previously suggested by the radiosonde composites. The AEJ was found to be located farther to the south on the clear nights, and the strongest winds were located directly above northern Benin. The cloudy nights, in contrast, featured a trough in the easterlies at approximately $0^{\circ} \mathrm{W}$. This trough in the composites may represent a "southern vortex" of an African Easterly Wave, per the definition of Fink and Reiner (2003). An alternative interpretation of such a wave south of the AEJ is that it may represent a 6-9 day wave, such as those described by Diedhiou et al (1999). As a third possibility, this circulation feature may be a quasistationary vortex, such as those described in Schrage et al (2006) and Fink et al (2006). Hovmoeller diagrams of the $700 \mathrm{hPa}$ meridional wind, averaged between $5^{\circ} \mathrm{N}$ and $10^{\circ} \mathrm{N}$, were constructed for each of the 11 cloudy cases (not shown). All but two of the cloudy nights exhibited a $700 \mathrm{hPa}$ trough in the vicinity of Parakou. Six of these troughs propagated westward at an average rate of $7.7^{\circ}$ longitude/day. which is in good agreement with the range of 6-8 $8^{\circ}$ longitude/day for African Easterly Waves cited by Reed et al (1977). The three remaining cases exhibited westward propagating troughs as well, but the phase speed was much slower, averaging $2.2^{\circ}$ longitude/day.

At $200 \mathrm{hPa}$ (Fig. 5a and d), the primary difference between the clear and cloudy nights appears to be in the magnitude of the TEJ. As suggested by the radiosonde composite profiles, the cloudy nights exhibited considerably stronger easterlies at this pressure level than the clear nights did. This lends some credence to the possibility that the $700 \mathrm{hPa}$ circulation feature was actually a stationary vortex, as Schrage et al (2006) described a very strong TEJ during a case of a vortex at $700 \mathrm{hPa}$ during the summer of 2002 .

In summary, the clear nights exhibited a surge of moist, low-level monsoonal southwesterlies, a strong, zonal flow in the AEJ and weak flow in the TEJ, whereas the cloudy nights had weaker, more meridional flow in the AEJ and an enhanced TEJ. In a different context, Gu and Adler (2004) described these same two patterns as an indication of changes in the large scale flow structure before and after the onset of precipitation along about $10^{\circ} \mathrm{N}$ on a seasonal timescale. Their pre-onset pattern superficially corresponds to the conditions observed on the clear nights, while after the onset of the monsoon the conditions where more similar to cloudy conditions in this study. Gu and Adler (2004) discussed these patterns in the context of mechanisms that support the abrupt northward movement of the surface convergence features in June and July, such as those suggested by Tai and Ogura (1987). An examination of the dates presented in Table 1 clearly shows that these conditions are not strictly limited to pre-onset and post-onset periods but rather can occur intermittently throughout the monsoon season. A similar example of an enhanced and equatorially-displaced AEJ was observed in August of 2000 by Thorncroft et al (2003) during an anomalously dry period in Niger. Similar patterns were noted by Sultan et al (2003) on intraseasonal time scales. On 


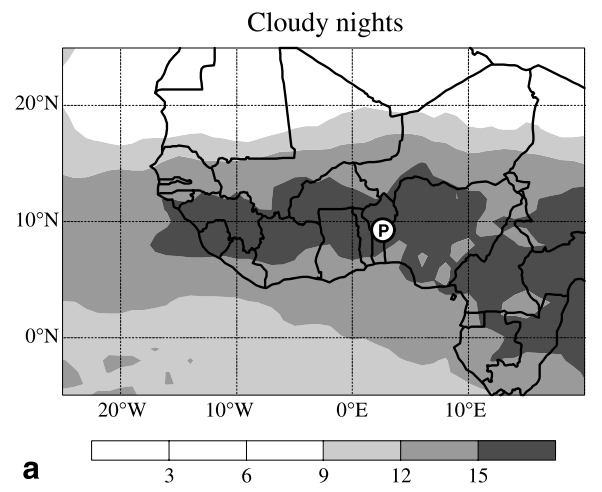

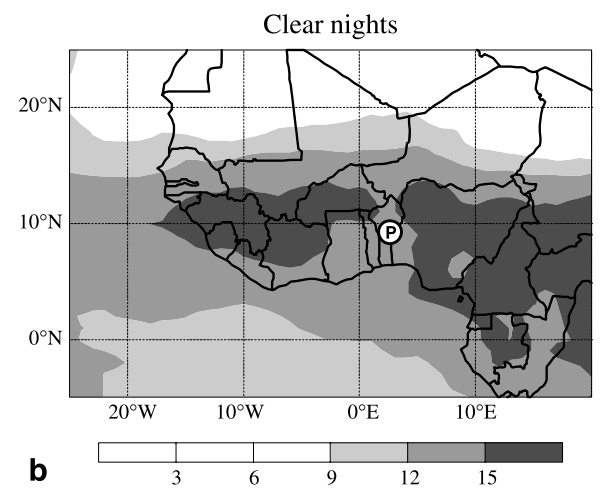

Fig. 6. Specific humidity $(\mathrm{g} / \mathrm{kg})$ at $925 \mathrm{hPa}$ according to ECMWF operational analyses, composited for (a) 11 cloudy nights, and (b) 12 clear nights. The location of Parakou is indicated with a "P" interannual time scales, Grist and Nicholson (2001) saw similar patterns in composites of dry and wet years in West Africa. On relatively short time scales, therefore, it may be the case that low-level nocturnal clouds can serve as an indicator of two distinct modes in which the circulation of West Africa can be configured.

\subsection{Moisture}

Composite fields of specific humidity at $925 \mathrm{hPa}$ for the cloudy and clear nights are presented in Fig. 6 using ECMWF operational model data. In both the cloudy and the clear nights, the axis of greatest specific humidity is found to be along approximately $10^{\circ} \mathrm{N}$, or approximately the latitudes of the Soudanian climate zone. Steep meridional moisture gradients existed both to the north and the south of this axis, with extremely low specific humidity values north of about $17^{\circ} \mathrm{N}$. The chief difference between the moisture fields in the cloudy and clear composites is a moderate reduction in the specific humidity values centered on Benin on the clear nights.

Since both the radiosonde composites and the ECMWF composites suggest that the clear nights have a drier boundary layer than the cloudy nights, some explanation of the changes in the humidity is necessary. Figure 7 depicts zonal averages of moisture advection $(-\vec{V} \cdot \nabla q)$, moisture divergence $(q \nabla \cdot \vec{V})$, and moisture flux divergence $(\nabla \cdot(q \vec{V}))$ between $5^{\circ} \mathrm{W}$ and $5^{\circ} \mathrm{E}$ at $925 \mathrm{hPa}$ for the cloudy and clear nights. Due to the positive meridional gradient of moisture and the southerly flow at $925 \mathrm{hPa}$, all latitudes south of about $12^{\circ} \mathrm{N}$ actually experienced dry air advection (Fig. 7a) on both the cloudy and the
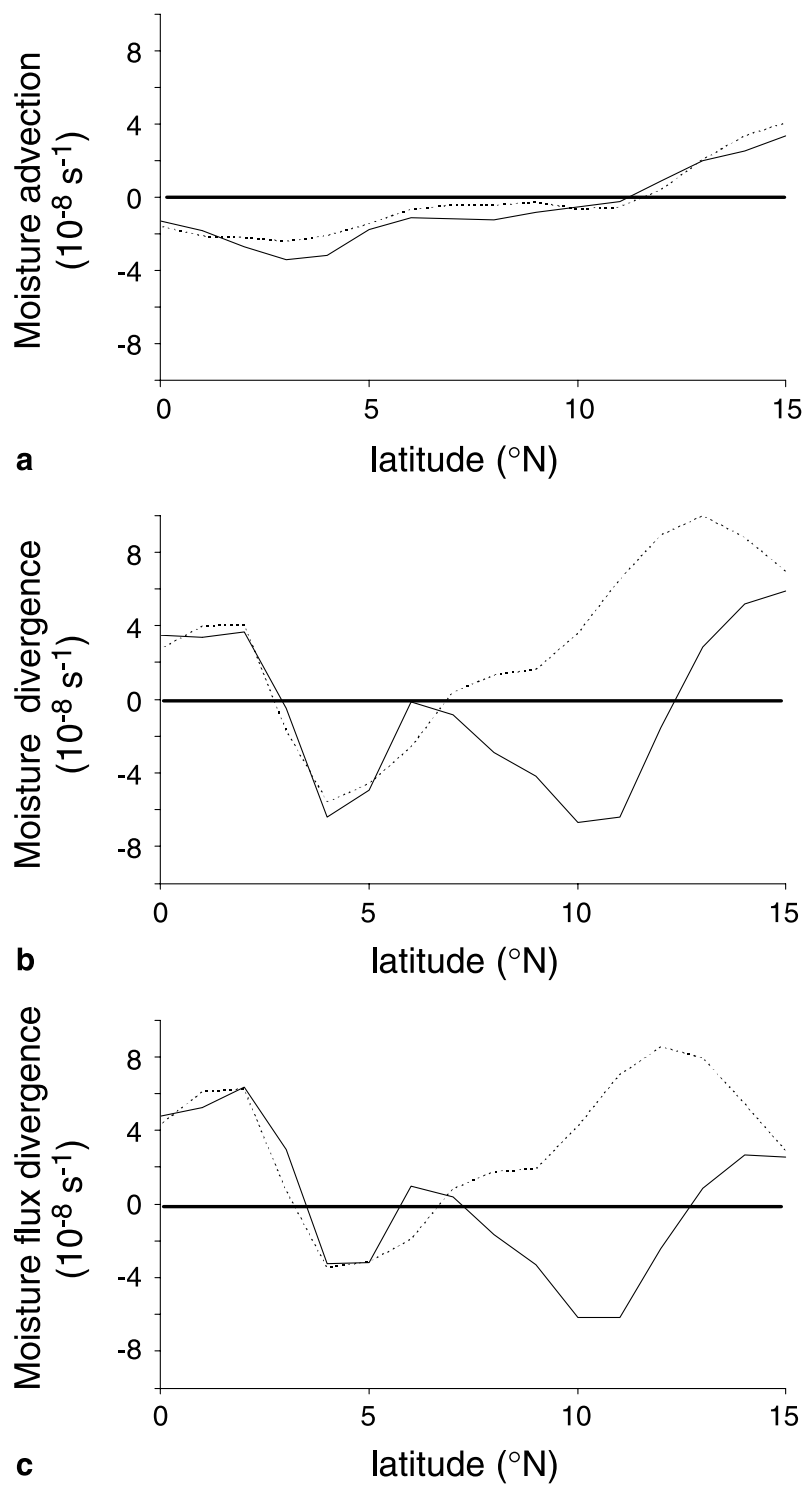

Fig. 7a. Moisture advection, (b) moisture divergence, and (c) moisture flux divergence in $10^{-8} \mathrm{~s}^{-1}$, zonally averaged between $5^{\circ} \mathrm{W}$ and $5^{\circ} \mathrm{E}$, for cloudy (solid) and clear (dotted) nights 
clear nights, with particularly impressive values noted on the cloudy nights along $4^{\circ} \mathrm{N}$, where southwesterly flow was especially strong. Conversely, strong moist air advection was noted north of the axis of highest specific humidity, as low-level monsoon flow transported moisture towards the heat low over the Sahara. Over most of the West African wet zones, the values of moisture advection are small, negative, and largely independent of the status of the cloud cover. Thus, it seems unlikely that the changes in the low-level cloudiness are due to changes in the moisture advection at $925 \mathrm{hPa}$. Note, however, that north of about $11^{\circ} \mathrm{N}$, the zonally averaged moisture advection is actually greater on the clear nights than on the cloudy nights. Sultan and Janicot (2003) postulated that an enhanced heat low increased meridional circulation and resulted in moisture advection just prior to the onset of a northward shift of the intertropical front in Sahelian West Africa.

Much greater differences between the cloudy and clear nights are seen in composite fields of the moisture divergence at $925 \mathrm{hPa}$ (Fig. 7b). On the cloudy nights, most of sub-Sahelian West Africa experienced strong large scale moisture convergence. The horizontal divergence of the wind was written in natural coordinates by Panofsky (1956, p. 35) as

$\nabla_{h} \cdot \vec{V}=\frac{\partial V}{\partial s}+\frac{V \pi}{180} \frac{\partial \alpha}{\partial n}$,

where $V$ is the magnitude of the velocity vector $\vec{V}, \alpha$ is the wind direction in degrees, $s$ is a coordinate tangent to the streamline of the flow, and $n$ is a coordinate at right angles to the flow. In this form, $\frac{\partial V}{\partial s}$ is the contribution to the total divergence by changes in the speed of the flow along a streamline; this term is commonly known as "speed divergence". An examination of the $925 \mathrm{hPa}$ streamlines and isotachs suggests that this moisture convergence is due to large scale speed convergence over the region. Conversely, the clear nights exhibited a weak signal in the Guineo-Soudanian zone $\left(6-11^{\circ} \mathrm{N}\right)$ and demonstrated significant moisture divergence at Sahelian latitudes poleward of $11^{\circ} \mathrm{N}$.

As readily seen in Fig. 7a and b, the moisture divergence is considerably larger than the moisture advection and, therefore, dominates the moisture flux divergence calculation (Fig. 7c).
As expected, most of sub-Saharan West Africa exhibited a net moisture flux convergence on the cloudy nights, whereas the clear nights showed evidence of slight moisture flux divergence at most latitudes. Neelin and Held (1987) noted that the moisture flux divergence field is largely determined by the mass divergence field because the kinematic fields vary on smaller spatial scales than the large-scale moisture field at low levels.

Since specific humidity is a positive-definite quantity, the sign of moisture divergence arises from the sign of the mass divergence. Therefore, the zero contour of moisture divergence (or, alternatively, the zero line in Fig. 7b) separates regions of positive and negative horizontal mass divergence at $925 \mathrm{hPa}$. An examination of the streamlines and isotachs of the composite flow (Fig. 5c and f) suggests overall speed convergence (i.e., $\partial V / \partial s<0$ ). It is noted that cloudy nights are characterized by strong large-scale speed convergence in the boundary layer, whereas clear nights exhibit less speed convergence at these levels, at least in the vicinity of Parakou.

\subsection{Low-level divergence}

The total divergence $(\nabla \cdot \vec{V})$ has a zonal $(\partial u / \partial x)$ and a meridional $(\partial v / \partial y)$ component. For the latitudes of this study (i.e., $25^{\circ} \mathrm{N}-5^{\circ} \mathrm{S}$ ), $925 \mathrm{hPa}$ values of divergence and its components were zonally averaged between $5^{\circ} \mathrm{W}$ and $5^{\circ} \mathrm{E}$. The results showed that the total divergence was highly correlated with $\partial v / \partial y(r=0.91$ and 0.97 on cloudy and clear nights, respectively) but poorly correlated to $\partial u / \partial x(r=0.43$ and 0.39 on cloudy and clear nights, respectively). The values of $\partial u / \partial x$ were typically an order of magnitude smaller than the values of $\partial v / \partial y$, especially between $4^{\circ} \mathrm{N}$ and $10^{\circ} \mathrm{N}$. Consequently, the processes supporting changes in the total divergence field at $925 \mathrm{hPa}$ were assumed to be related to changes in the meridional contribution to total divergence.

In isobaric coordinates, the horizontal momentum equation for the meridional component of the wind can be written as

$\frac{\partial v}{\partial t}+u \frac{\partial v}{\partial x}+v \frac{\partial v}{\partial y}+f u+F_{y}=-\frac{\partial \Phi}{\partial y}$ 
where $F_{y}$ is the component of friction in the meridional direction and $\Phi=g z$. Assuming steady state conditions, this expression can be rearranged as

$\frac{\partial v}{\partial y}=\underbrace{-\frac{1}{v} \frac{\partial \Phi}{\partial y}}_{A} \underbrace{-f \frac{u}{v}}_{B} \underbrace{-\frac{u}{v} \frac{\partial v}{\partial x}}_{C} \underbrace{-\frac{F_{y}}{v}}_{D}$.

Therefore, the divergence in the meridional direction (i.e., the left-hand side of Eq. (2)) can be explained by four terms, three of which can be computed from the ECMWF operational analyses. Friction (term d) can be calculated as a residual. Meridional profiles of these terms at $925 \mathrm{hPa}$ along $2^{\circ} \mathrm{E}$ (i.e., the approximate longitude of Parakou) are presented in Fig. 8. For these terms, positive values contribute to divergence in the meridional plane, whereas negative values contribute to convergence.

Changes in the geopotential height pattern on the $925 \mathrm{hPa}$ surface (not shown) suggested that cloudy nights experience an enhanced meridional pressure gradient poleward of the Soudanian climate zone, suggesting that meridional winds should accelerate northward in this region on those nights, favoring low-level divergence. Figure 8a supports this conclusion by illustrating that the magnitude of term $\mathrm{A}$ from equation 2 is significantly greater on cloudy nights than on clear nights north of about $10^{\circ} \mathrm{N}$. This term opposes the observed effect of enhanced convergence at $925 \mathrm{hPa}$ on cloudy nights (based on the moisture divergence curve shown in Fig. 7b). Therefore, the effects of the enhanced low-level divergence driven by changes in the geopotential height pattern must be overwhelmed by convergence driven by another term in Eq. (2).

Figure $8 \mathrm{~b}$ illustrates that the zonally-averaged values of term B from Eq. (2) at $925 \mathrm{hPa}$ do not vary greatly between the cloudy and the clear nights. The primary difference seems to occur at about $6^{\circ} \mathrm{N}$, where enhanced southerly winds on cloudy nights increase the value of $v$ in the denominator, reducing the impact of this term. Similarly, term C (Fig. 8c) was found to be small at all latitudes of interest.

Fig. 8. Terms (a) A, (b) B, (c) C, and (d) D of Eq. (2), and (e) $\partial v / \partial y$, zonally averaged between $5^{\circ} \mathrm{W}$ and $5^{\circ} \mathrm{E}$ at $925 \mathrm{hPa}$, in $10^{-5} \mathrm{~s}^{-1}$ for cloudy nights (solid) and clear nights (dashed)
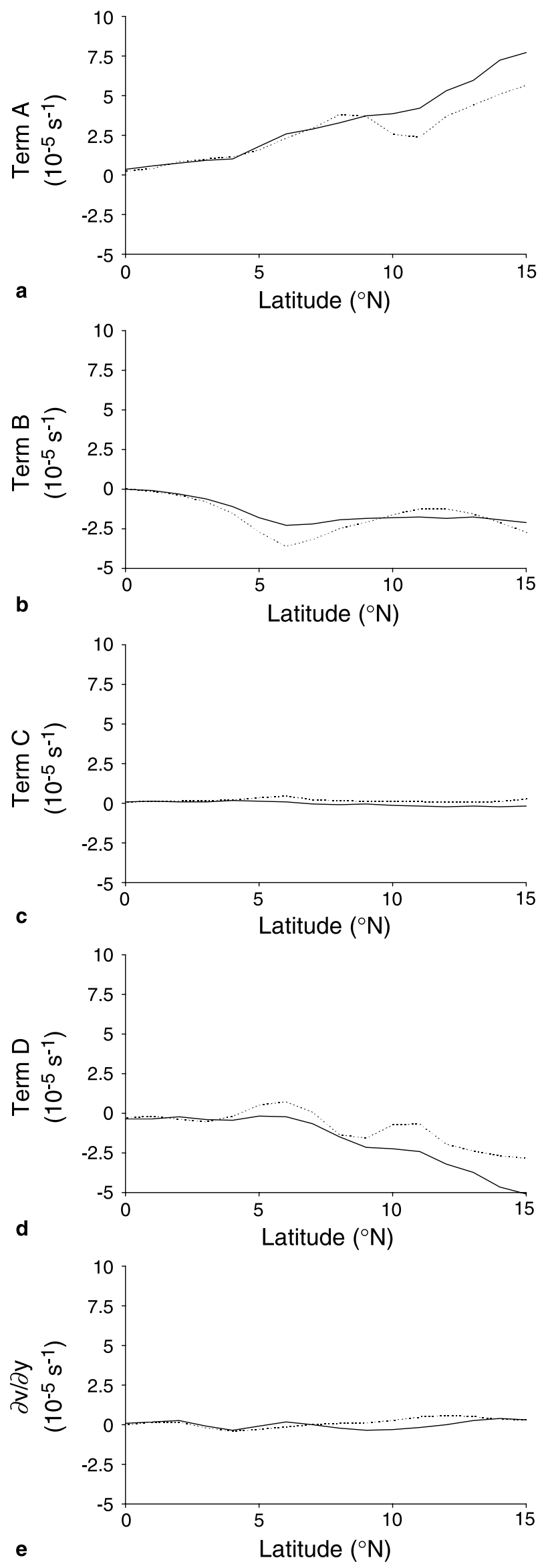
Significant differences between cloudy and clear nights were found in term D (Fig. 8d) at several important latitudes. At most inland latitudes, the contribution of this frictional term to low-level convergence was greater on the cloudy nights than on the clear nights.

Frictional drag may present an important positive feedback for the maintenance of nocturnal stratiform cloud decks during the West African monsoon. Cloudy nights have been shown to be capable of persistent production of thermals and maintenance of a well-defined mixed layer (see Fig. 2). On these nights, the boundary layer remains well-coupled to the surface by a superadiabatic layer very near the surface. Consequently, the frictional drag in the boundary layer remains high, and winds flowing ashore from the Atlantic Ocean will experience signifi-

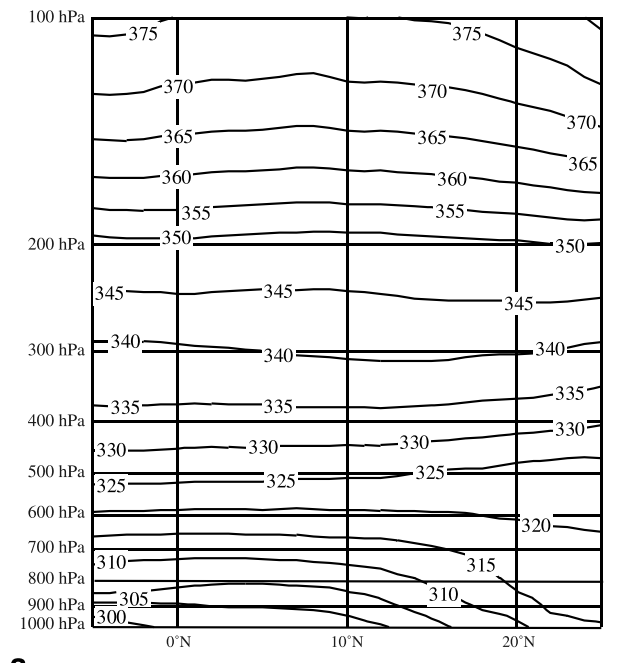

a

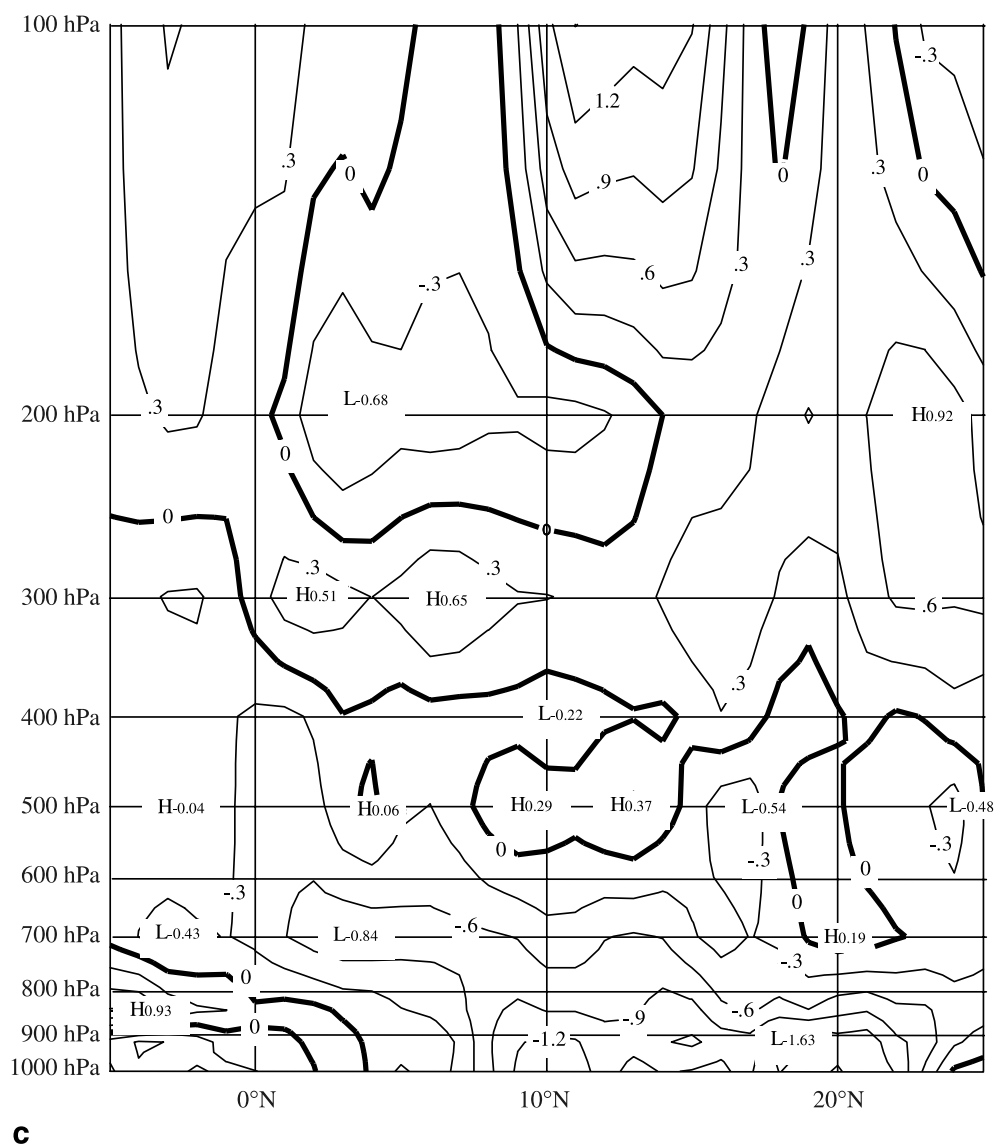

Fig. 9. Meridional cross sections of potential temperature along $2^{\circ} \mathrm{E}$ according to ECMWF operational analyses, composited for (a) 11 cloudy nights, and (b) 12 clear nights. Panel c represents the difference between cloudy and clear nights 
cant speed convergence. This speed convergence results in a net positive moisture flux convergence in the boundary layer, increasing the probability that the rising thermals will result in low cloud production. These stratiform clouds reduce net longwave emission by the surface, helping maintain the instability that kept the boundary layer coupled to the surface. Conversely, on clear nights the coupling of the boundary layer to the surface is greatly diminished by the presence of a strong nocturnal inversion. Winds even a few tens of meters above the surface are largely unaffected by the underlying surface and do not experience substantial frictional drag. Speed convergence is therefore diminished, reducing moisture convergence and making low cloud cover less likely. The reduced cloud cover allows for more radiational cooling of the surface, maintaining the nocturnal inversion that reduced frictional drag. A similar process was described by May (1995) for the nocturnal jet over Australia, in which cloud cover influenced the coupling of the surface to lower-level winds.

\subsection{Maintenance of the TEJ and AEJ by the thermal wind}

Both the radiosonde observations from Parakou and the ECMWF operational analyses demonstrated consistent differences in the large-scale flow regimes on cloudy nights when compared to clear nights. As the AEJ and TEJ can both be reasonably assumed to be in Thermal Wind balance, differences in the meridional temperature gradients along $2^{\circ} \mathrm{E}$ (i.e., the approximate longitude of Parakou, Benin) are useful in explaining the changes in the flow.

The meridional cross section of potential temperature along $2^{\circ} \mathrm{E}$ from the ECMWF operational analyses is presented in Fig. 9. Both the cloudy (Fig. 9a) and the clear nights (Fig. 9b) exhibit the expected key features of the region, such as a relatively cool monsoon layer that is moderately stable, a hot SAL that is approximately statically neutral (i.e., $\partial \theta / \partial P \approx 0$ ), and an upper troposphere that is strongly stable. The difference field (Fig. 9c) clearly indicates that cloudy nights are cooler near the surface at Sahelian and Saharan latitudes, although the cause of this change cannot be determined by this analysis. Below about $700 \mathrm{hPa}$, the cooler conditions to the north on cloudy nights imply that the meridional temperature gradient $\partial T / \partial y$ is smaller at about $8^{\circ} \mathrm{N}$ through the depth of the lower troposphere. By thermal wind balance, the AEJ at $700 \mathrm{hPa}$ should therefore be weaker on the cloudy nights, which is consistent with both the observations and the model analyses.

By a similar analysis, the enhanced TEJ on cloudy nights is consistent with warm conditions at about $300 \mathrm{hPa}$ between about $0^{\circ} \mathrm{N}$ and $10^{\circ} \mathrm{N}$ (Fig. 9c). The resulting meridional temperature gradient along $300 \mathrm{hPa}$ at these latitudes implies that the zonal component of the geostrophic wind should decrease (that is, become increasingly negative) with respect to height.

\section{Conclusions and future work}

The presence or absence of extensive nocturnal stratiform cloud decks in the wet Soudanian zone during the peak of the West African summer monsoon season has been found to be related to a number of key features of the monsoon atmosphere. Clear nights occurred when the formation of a nocturnal inversion in the lower atmosphere promoted decoupling of the surface and lower atmosphere. The resulting reduced frictional drag coincided with moisture flux divergence in the boundary layer, lowering overall moisture content and preventing cloud cover, which permitted further radiational cooling at the surface. Nocturnal stratiform cloud decks tended to form on nights in which production of buoyant thermals continued well after sunset. The statically neutral boundary layer remained tightly coupled to the surface, increasing overall frictional drag and shear stresses. Consequently, the West African wet zone experienced speed convergence and a net positive moisture flux convergence. The resulting cloud cover reduced net longwave emission by the surface, helping maintain the low-level instability. Observations taken during the 2002 IMPETUS field campaign indicate that the stratiform cloud deck persisted until noon and often disappeared rapidly after the 1200 UTC sounding. Unfortunately, a morning and afternoon sounding was not taken to allow for a better description of the diurnal boundary layer evolution. High frequency soundings as well as a meridional transect of the flux stations along $2^{\circ} \mathrm{E}$, as planned during the 2006 field cam- 
paign of the AMMA (African Monsoon Multidisciplinary Analysis) project, will enable a more thorough investigation of the diurnal cycle in surface fluxes and boundary-layer evolution.

Cloudy nights were found to occur in flow regimes with a strong southwesterly monsoon flow in the Guineo-Soudanian zone, a weak AEJ and an enhanced TEJ, while the reverse was the case for the clear nights. Overall, the clear nights show some features of the conditions typical of the "pre-onset" period of the monsoon before mid June, whereas the cloudy nights display features commonly observed during the fully developed monsoon. An examination of the dates listed in Table 1 suggests that differences noted are probably not related to intraseasonal monsoon breaks but rather day-to-day synoptic changes in the monsoon structure.

The composite clear night circulation was in some way reminiscent of the nocturnal circulation patterns described by Parker et al (2005), with monsoon southwesterlies at low levels, but northerly flow and drier air at midlevels. Parker et al noted that convective mixing in the daytime disrupted this noctural pattern; in the case of the cloudy nights, persistent mixing at 0000 UTC seems to be having the same effect.

The inverse relationship between the magnitudes of the AEJ and TEJ has been noted by other authors on other time scales (e.g., Grist and Nicholson, 2001; Sultan et al, 2003; Thorncroft et al, 2003; Gu and Adler, 2004). A case can be made that the modulation of the AEJ is consistent with changes in the meridional temperature structure below about $700 \mathrm{hPa}$, although the explanation for the TEJ is less satisfying. Regardless, the analysis cannot explain the relatively cool conditions from $10^{\circ} \mathrm{N}$ to farther than $20^{\circ} \mathrm{N}$ near the surface on cloudy nights (or, alternatively, the relatively warm conditions on clear nights) in Benin. As an examination of Fig. 9 clearly shows that the greatest temperature differences occur near the surface, it seems reasonable to speculate that the phenomena are driven by modulation of surface temperature. It is possible, but beyond the present study, that high clouds over the Sahel and the Sahara during the day yield a cooler surface and ultimately a cooler SAL on the following night. Further studies will attempt to determine what processes cause the significant changes in the meridional temperature structure that seem to be fundamental to diagnosing the overall modes of circulation in the West African monsoon.

\section{References}

Cadet BL, Nnoli NO (1987) Water vapor transport over Africa and the Atlantic Ocean during summer 1979. Quart J Roy Meteorol Soc 113: 581-602

Dhonneur G (1981) Les amas nuageux mobiles principale composante de la météorologie du Sahel. La Météorologie 27: 75-82

Diedhiou A, Janicot S, Viltard A, de Felice P, Laurent H (1999) Easterly wave regimes and associated convection over West Africa and tropical Atlantic: results from the NCEP/NCAR and ECMWF reanalyses. Climate Dyn 15: $795-822$

Douville H (2002) Influence of soil moisture on the Asian and African monsoons, part II: Interannual variability. J Climate 15: 701-720

Douville H, Chauvin F, Broqua H (2001) Influence of soil moisture on the Asian and African monsoons, part I: Mean monsoon and daily precipitation. J Climate 14: 2381-2403

Dunion J, Velden C (2004) The impact of the Saharan air layer on Atlantic tropical cyclone activity. Bull Amer Meteor Soc 85(3): 353-365

Farquharson JS (1939) The diurnal variation of wind over tropical Africa. Quart J Roy Meteorol Soc 65: 165-183

Fink AH, Reiner A (2003) Spatiotemporal variability of the relation between African easterly waves and West African squall lines in 1998 and 1999. J Geophys Res 108(D11): 4332 (DOI:10.1029/2002JD002816)

Fink AH, Vincent DG, Ermert V (2006) Rainfall types in the West African soudanian zone during the summer monsoon 2002. Mon Wea Rev (accepted)

Grist JP, Nicholson SE (2001) A study of dynamic factors influencing the rainfall variability in the West African Sahel. J Climate 14: 1337-1359

Gu G, Adler RF (2004) Seasonal evolution and variability associated with the West African monsoon system. J Climate 17: 3364-3377

Hsieh J-S, Cook KH (2005) Generation of African easterly wave disturbances: Relationship to the African easterly jet. Mon Wea Rev 133: 1311-1327

Lamb PJ (1983) West African water vapor variations between recent contrasting Subsaharan rainy seasons. Tellus 35A: 198-212

Lloyd CR, Bessemoulin P, Cropley FD, Culf AD, Dolman AJ, Elbers J, Heusinkveld B, Moncrieff JB, Monteny B, Verhoef A (1997) A comparison of surface fluxes at the HAPEX-Sahel fallow bush sites. J Hydrol 189: 400-425

Mathon V, Laurent H, Lebel T (2002) Mesoscale convective system rainfall in the Sahel. J Appl Meteor 41: 1081-1092

May PT (1995) The Australian nocturnal jet and diurnal variations of boundary-layer winds over Mt. Isa in northeastern Australia. Quart J Roy Meteor Soc 121: 987-1003 
Neelin JD, Held IM (1987) Modeling tropical convergence based on the moist static energy budget. Mon Wea Rev 115: 3-12

Panofsky HA (1956) Introduction to Dynamic Meteorology, Pennsylvania State University, $243 \mathrm{pp}$

Parker DJ, Burton RR, Diongue A, Ellis RJ, Felton M, Taylor CM, Thorncroft CD, Bessemoulin P, Tompkins AM (2005) The diurnal cycle of the West African monsoon circulation. Quart J Roy Meteor Soc to appear in the October 2005 edition

Redelsperger J-L, Diongue A, Diedhiou A, Ceron J-P, Diop M, Gueremy J-F, Lafore J-P (2002) Multi-scale description of a Sahelian synoptic weather system representative of the West African monsoon. Quart J Roy Meteor Soc 128: 1229-1257

Reed RJ, Norquist DC, Recker EE (1977) The structure and properties of African wave disturbances observed during Phase III of GATE. Mon Wea Rev 105: 317-333

Schrage JM, Fink AH, Ermert V, Ahlonsou ED (2006) Three MCS cases occurring in different synoptic environments in the sub-Sahelian wet zone during the 2002 West African monsoon. J Atmos Sci (submitted)

Sultan B, Janicot S (2003) The West African monsoon dynamics, part II: The "preonset" and "onset" of the summer monsoon. J Climate 16: 3407-3427

Sultan B, Janicot S, Diedhiou A (2003) The West African monsoon dynamics, part I: Documentation of intraseasonal variability. J Climate 16: 3389-3406
Tai K-S, Ogura Y (1987) An observational study of easterly waves over the eastern Pacific in the northern summer using FGGE data. J Atmos Sci 44: 339-361

Taylor CM, Clark DB (2001) The diurnal cycle and African easterly waves: A land surface perspective. Quart J Roy Meteorol Soc 127: 845-867

Taylor CM, Parker DJ, Lloyd CR, Thorncroft CD (2005) Observations of synoptic scale land surface variability and its coupling with the atmosphere. Quart J Roy Meteorol Soc 131: 913-938

Thorncroft CD, Parker DJ, Burton RR, Diop M, Ayers JH, Barjat H, Devereau S, Diongue A, Dumelow R, Kindred DR, Price NM, Saloum M, Tayor CM, Tompkins AM (2003) The JET2000 project: Aircraft observations of the African easterly jet and African easterly waves. Bull Amer Met Soc 84: 337-351

Tompkins AM, Cardinali C, Morcrette J-J, Rodwell M (2005) Influence of aerosol climatology on forecasts of the African easterly jet. Geophys Res Lett 32: L10801 (DOI:10.1029/2004GL022189)

Zeng N, Neelin JD, Lau K-M, Tucker CJ (1999) Enhancement of interdecadal climate variability in the Sahel by vegetation interaction. Science 286: 1537-1540

Corresponding author's address: Jon M. Schrage, Department of Environmental and Atmospheric Sciences, Creighton University, 2500 California Plaza, Omaha, NE 68178, USA (E-mail: jon@creighton.edu) 